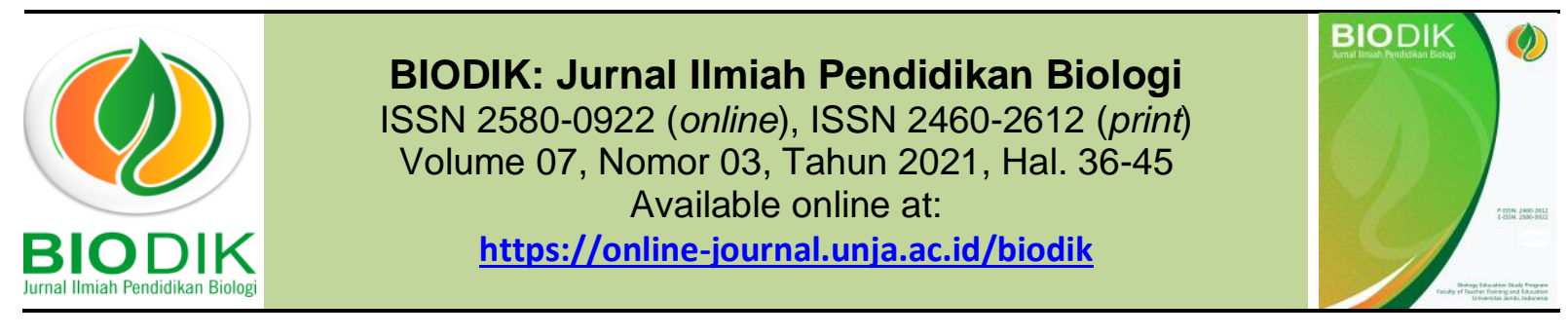

Research Article

OPEN ACCESS

\title{
Rekonstruksi DKL Materi Pteridophyta: Fenetik sebagai Sebuah Pendekatan
}

\section{(Reconstruction of Practical Activity Design on Pteridophyta Materials: Phenetics as an Approach)}

\author{
Pipin Puja Lestari*, Sri Anggraeni, Bambang Supriatno \\ Universitas Pendidikan Indonesia
}

JI. Dr. Setiabudi No.229, Isola, Kec. Sukasari, Kota Bandung, Jawa Barat 40154

*Coressponding Author: pipinpuja89@.gmail.com

\begin{tabular}{|c|c|}
\hline Informasi Artikel & ABSTRACT \\
\hline $\begin{array}{l}\text { Submit: } 02-06-2021 \\
\text { Diterima: } 12-08-2021 \\
\text { Dipublikasikan: } 16-09-2021\end{array}$ & $\begin{array}{l}\text { Education } 4.0 \text { focuses on improving } 21 s t \text { century skills, one of which is science } \\
\text { process skills, especially communication skills on Pteridophyta material. } \\
\text { However, the existing DKL as practicum support is not optimal. The purpose of } \\
\text { this study was to analyze the quality of DKL on pteridophyta (ferns) materials } \\
\text { used in schools in recent curricula covering aspects of curriculum relevance, } \\
\text { competence, and knowledge construction. Then a trial was conducted on one of } \\
\text { the DKL. The findings from the analysis and trials became the basis for the } \\
\text { reconstruction of Pteridophyta DKL. The results of the research show that the } \\
\text { existing DKL still has not developed higher-order thinking skills, and there are } \\
\text { still few concepts formed. The results of the DKL reconstruction use a phenetic } \\
\text { approach to make it more effective and representative according to the demands } \\
\text { of the applicable KD and develop communication skills. } \\
\text { Key words: Practicum, Pteridophyta, Design of laboratory activities, Phenetic } \\
\text { Approach }\end{array}$ \\
\hline Penerbit & ABSTRAK \\
\hline \multirow[t]{2}{*}{$\begin{array}{l}\text { Program Studi Pendidikan Biologi } \\
\text { FKIP Universitas Jambi, } \\
\text { Jambi- Indonesia }\end{array}$} & $\begin{array}{l}\text { Pendidikan } 4.0 \text { berfokus pada peningkatan keterampilan abad ke-21, salah } \\
\text { satunya keterampilan proses sains khususnya keterampilan berkomunikasi } \\
\text { pada materi Pteridophyta. Namun DKL yang ada sebagai penunjang praktikum } \\
\text { belum optimal. Tujuan penelitian ini adalah untuk menganalisis kualitas DKL } \\
\text { pada materi pteridophyta (tumbuhan paku) yang digunakan di sekolah dalam } \\
\text { beberapa kurikulum terakhir meliputi aspek relevansi kurikulum, kompetensi, } \\
\text { dan konstruksi pengetahuan. Lalu dilakukan uji coba pada salah satu DKL. } \\
\text { Temuan dari analisis dan uji coba menjadi dasar rekonstruksi DKL Pteridophyta. } \\
\text { Hasil penellitian menunjukan bahwa DKL yang ada masih belum } \\
\text { mengembangkan kemampuan berpikirtingkattinggi, dan masih minimya konsep } \\
\text { yang terbentuk. Hasil rekonstruksi DKL menggunakan pendekatan fenetik agar } \\
\text { lebih efektif dan representatif sesuai tuntutan KD yang berlaku dan } \\
\text { mengembangkan keterampilan berkomunikasi. }\end{array}$ \\
\hline & $\begin{array}{l}\text { Kata kunci: Praktikum, Pteridophyta, Desain Kegiatan Laboratorium, } \\
\text { Pendekatan Fenetik }\end{array}$ \\
\hline
\end{tabular}

This BIODIK : Jurnal IImiah Pendidikan Biologi is licensed under a CC BY-NC-SA (Creative Commons Attribution-ShareAlike 4.0 International License) 


\section{PENDAHULUAN}

Era revolusi industri telah memberikan dampak yang sangat besar pada berbagai bidang, salah satunya pendidikan. Kualitas SDM dapat ditingkatkan melalui jalur pendidikan mulai dari pendidikan dasar hingga ke perguruan tinggi sebagai kunci agar mampu mengikuti perkembangan Revolusi Industri 4.0 (Lase, 2019). Fisk membagi sembilan tren pendidikan 4.0 yang menjadi tanggung jawab utama guru kepada peserta didik. Adaptasi terhadap tren pendidikan ini memberi garansi bagi individu dan masyarakat untuk mengembangkan serangkaian kompetensi, keterampilan, dan pengetahuan yang lebih lengkap dan mengeluarkan seluruh potensi kreatif mereka sebagai bekal hidup mereka di abad ke-21 ini (Lase, 2019). Salah satu keterampilan yang dapat dikembangkan untuk mempersiapkan peserta didik pada abad 21 adalah Keterampilan Proses Sains (Sisri et al., n.d.).

Salah satu keterampilan proses yang dituntut oleh kurikulum saat ini adalah keterampilan berkomunikasi, misalnya setiap peneliti biologi dituntut agar mampu menyampaikan hasil penemuannya kepada orang lain. Hasil tersebut dapat disampaikan dalam bentuk laporan penelitian atau paper, dapat pula disampaikan secara lisan. Sering juga hasil penelitian tersebut dibuat dalam bentuk gambar, model, tabel, grafik atau histogram (Oktaviani \& Hidayat, 2015). Untuk meningkatkan keterampilan berkomunikasi peserta didik banyak cara yang bisa ditempuh, salah satunya dengan menggunakan metode fenetik. Fenetik merupakan salah satu metode dalam sistematik yang dapat menaksir hubungan evolusi berdasarkan kepemilikan karakter atau ciri yang sama (overall similarity) dari anggota-anggota suatu kelompok (Hidayat, 2017).

Dalam dunia pendidikan kita, taksonomi dan evolusi tumbuhan (Plantae) telah menjadi bagian terpenting dalam kurikulum dari mulai tingkat sekolah dasar sampai perguruan tinggi dengan berbagai modifikasi yang disesuaikan dengan perkembangan intelektual mereka. Meskipun belum ada data yang signifikan, perhatian peserta didik terhadap materi tumbuhan ini cenderung rendah. Mereka memandang materi ini penuh dengan hapalan sehingga membosankan. Menurut Harvey \& Pagel (dalam Hidayat, 2017) yang menjadi inti permasalahan terletak pada kurangnya penugasan (workable assignments) yang diberikan oleh guru kepada peserta didik selama pembelajaran di kelas berlangsung.

Pembelajaran biologi tidak dapat terpisahkan dari kegiatan praktikum atau kegiatan laboratorium. Kegiatan praktikum dilakukan untuk memberikan pengalaman belajar yang mencakup penemuan konsep dari fakta yang ada, membelajarkan proses menemukan suatu konsep, dan melatih keterampilan proses sains yang didalamnya mencakup keterampilan observasi, mengajukan hipotesis, memprediksi, interpretasi data, mengkomunikasikan data, menerapkan konsep, mengklasifikasikan, merancang percobaan, dan melaksanakan percobaan. Pengalaman melalui kegiatan laboratotium merupakan bagian hands on yang secara langsung melibatkan siswa kedalam kegiatan mengumpulkan dan menganalisis informasi, menggambarkan penyelesaian, membuat grafik, peta, gambar, atau kertas kerja untuk membantu mereka berpikir kritis dan mengkomunikasikan (Wahidah, N.S, Suptriatno, B, Kusumastuti, 2018)(Laelasari \& Supriatno, 2018).

Salah satu materi biologi yang hampir selalu dilaksanakan kegiatan praktikum adalah materi Plantae. Materi Plantae mencakup bahasan tentang Bryophyta, Pteridophyta dan Spermatophyta. Berdasarkan hasil observasi terhadap ketersediaan DKL tentang Plantae di sekolah paling banyak dilakukan adalah praktikum tentang Spermatophyta. Berdasarkan saran kegiatan dari kurikulum pada silabus kurikulum 2013 revisi, pada materi Plantae (Bryophyta, Pteridophyta, dan Spermatophyta) peserta didik diharapkan mampu menyajikan laporan hasil pengamatan dan analisis fenetik dan filogenetik tumbuhan serta peranannya dalam kehidupan. Sedangkan praktikum tentang materi Plantae terutama Pteridophyta yang umum dilakukan hanya barupa pengamatan ciri-ciri yang masih bersifat verifikatif saja. 
Berdasarkan uraian diatas, untuk menunjang kebutuhan tuntutan keterampilan komunikasi melalui kegiatan praktikum biologi khususnya materi pteridophyta, maka diperlukan sebuah desain kegatan laboratorium yang menggunakan pendekatan fenetik sebagai bentuk penugasan untuk menguji hubungan evolusi/kekerabatan dalam kelompok tumbuhan paku (Pteridophyta). Penugasan yang diberikan semestinya mengilustrasikan bagaimana para ilmuwan biologi atau ahli taksonomi bekerja untuk melakukan pengujian terhadap hipotesis tentang pola hubungan evolusi/kekerabatan dalam sebuah kelompok tumbuhan, dalam hal ini ini tumbuhan paku (Pteridophyta), sehingga peserta didik tidak lagi menganggap materi ini bersifat deskriptif dan spekulatif, sulit untuk dibuktikan.

\section{METODE PENELITIAN}

Penelitian ini menggunakan metode deskriptif untuk memperoleh gambaran mengenai kualitas Desain Kegiatan Laboratorium (DKL) Pteridophyta yang tersedia di lapangan untuk mengembangkan DKL rekonstruksi. Teknik sampling dilakukan secara purposive, dimana sampel DKL yang dianalisis berasal dari 5 buku ajar biologi yang berlaku pada beberapa kurikulum terakhir yang dapat ditemukan, diantaranya 2 DKL berbasis Kurikulum 1994 (GBPP1999), 1 DKL berbasis kurikulum 2004 (KBK), dan 2 DKL berbasis Kurikulum 2013. Pengembangan DKL dalam penelitian ini menggunakan pendekatan Analisis, Uji Coba dan Rekonstruksi (ANCOR) (Supriatno dalam Nurpratiwi, 2020). Alur penelitian dapat dilihat pada Gambar 1. Tahap Analisis DKL meliputi aspek relevansi dengan kurikulum, kompetensi, dan konstruksi pengetahuan. Setelah dilakukan analisis, salah satu DKL dari kurikulum terbaru dipiih untuk diuji coba dengan mengikuti seluruh petunjuk praktikum yang terdapat pada DKL tersebut. Berdasarkan hasil temuan analisis dan uji coba, maka tahap terakhir yaitu merekonstruksi dan membuat DKL dengan memperbaiki permasalahan yang ada pada DKL sebelumnya.

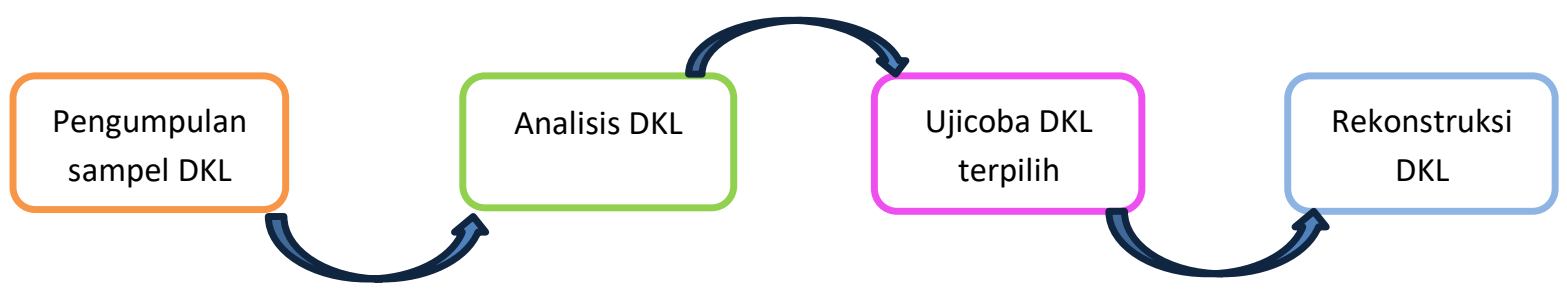

\section{Gambar 1. Alur Penelitian}

\section{HASIL PENELITIAN DAN PEMBAHASAN}

\section{Hasil Analisis Aspek Relevansi Kurikulum, Kompetensi dan Konstruksi Pengetahuan}

Analisis Relevansi didasarkan pada komponen kegiatan praktikum meliputi isi kegiatan praktikum yang tergambar melalui kesesuaian antara judul/tujuan, langkah kegiatan, proses pengamatan, dan hasil pengamatan dengan Kompetensi Dasar (KD) pada kurikulum yang berlaku pada saat DKL tersebut dibuat. Untuk menganalisis relevansi pada praktikum Pteridophyta, dilakukan analisis DKL berdasarkan pada dua parameter yaitu kesesuaian kompetensi dalam kegiatan yang mendukung untuk mencapai tuntutan KD dan kesesuaian konten yang meliputi kedalaman konten dalam kegiatan praktikum. Kompetensi dalam kegiatan praktikum diperoleh berdasarkan level pengetahuan. Perolehan skor hasil analisis aspek relevansi ditunjukkan pada Tabel 1.

Tabel 1. Hasil Analisis Aspek Relevansi 


\begin{tabular}{lllllll}
\hline & A & B & C & D & E & \\
\hline Kompetensi dengan KD. & 2 & 2 & 2 & 2 & 1 & 1,8 \\
\hline Konten dengan KD. & 2 & 2 & 2 & 2 & 1 & 1,8 \\
\hline
\end{tabular}

Berdasarkan hasil analisis seperti yang terlihat pada tabel 1, dapat disimpulkan bahwa dari segi kompetensi maupun konten hampir seluruh DKL dari kurikulum 1994 hingga 2013 sudah memenuhi tuntutan KD. Sehingga dapat dinyatakan bahwa hampir seluruh DKL yang dianalisis relevan dengan kurikulum. Hanya ada 1 DKL yang digunakan pada kurikulum 2013 edisi revisi yang kompetensi dan kontennya dinilai tidak sesuai dengan tuntutan KD. Adapun KD yang terdapat pada kurikulum tersebut adalah KD 3.8. Mengelompokkan tumbuhan ke dalam divisio berdasarkan ciri-ciri umum, serta mengaitkan peranannya dalam kehidupan dan KD 4.8. Menyajikan laporan hasil pengamatan dan analisis fenetik dan filogenetik tumbuhan serta peranannya dalam kehidupan. Akan tetapi, pada DKL E hanya mengamati ciri-ciri umum pteridophyta (tumbuhan paku) tanpa ada tindak lanjut pengelompokan dan kegiatan lainnya.

Aspek kedua yang dianalisis adalah aspek kompetensi. Analisis kompetensi dilakukan untuk mengetahui sejauh mana kegiatan praktikum dapat mengembangkan kemampuan-kemampuan siswa seperti kemampuan berpikir, kemampuan obsevasi, keterampilan representasi data, dan keterampilan menginterpretasi data. Analisis ini didasarkan pada tuntutan kegiatan yaitu komponen langkah kerja, perekaman data, dan pertanyaan pengarah pada DKL. Hasil analisis aspek kompetensi dapat dilihat pada tabel 2 berikut.

Tabel 2. Hasil Analisis Aspek Kompetensi

\begin{tabular}{|c|c|c|c|c|c|c|}
\hline \multirow[t]{2}{*}{ Parameter } & \multicolumn{5}{|c|}{ LKPD } & \multirow[t]{2}{*}{ Skor } \\
\hline & A & B & C & D & E & \\
\hline Kemampuan Observasi & 2 & 3 & 4 & 2 & 2 & 2,6 \\
\hline Transformasi (Miles\& Huberman, 1984) dan (Fisher et al, 1990) & 2 & 2 & 2 & 2 & 2 & 2 \\
\hline Interpretasi (Creswell, 2008) dan (Bertin,1983) & 1 & 1 & 1 & 1 & 1 & 1 \\
\hline Level Kemampuan berpikir (Anderson \& Krathwohl, 2001) & 1 & 1 & 1 & 1 & 1 & 1 \\
\hline
\end{tabular}

Berdasarkan hasil analisis, dapat disimpulkan bahwa dari segi kemampuan observasi, hampir seluruh DKL dari kurikulum 1994 hingga 2013 hanya mengobservasi karakter umum dari objek/fenomena. Hanya DKL B dan C yang mengobservasi karakter spesifik dari objek fenomena. Sedangkan dari segi Interpretasi dan level kemampuan berpikir, seluruh DKL dari kurikulum 1994 hingga 2013 yang dianalisis memiliki nilai sama yaitu 1 , yang artinya data tidak diinterpretasi. Temuan pada aspek representasi data menunjukan bahwa pada hampir seluruh DKL kegiatan tidak ditemukan kegiatan pengubahan bentuk data, bahkan terdapat DKL yang tidak menuntut kegiatan penyajian data atau representasi data yang baik. Proses Interpretasi hanya menggunakan beberapa komponen data (berupa gambar hasil pengamatan). Sedangkan salah satu keterampilan yang perlu dikuasai oleh siswa yang belajar sains adalah keterampilan interpretasi data, karena interpretasi data berkaitan dengan pemahaman dan pemberian makna terhadap data atau informasi (Murni et al., 2017). Selain itu, permasalahan juga muncul ketika DKL yang merupakan DKL kurikulum 2013 revisi tidak dapat mengembangkan kemampuan berpikir tingkat tinggi padahal sudah ada dalam tuntutan kurikulum. Kemampuan berpikir tingkat tinggi dapat dikatakan berhasil apabila siswa terlibat di dalam pembelajaran dan mampu mengonstruksi penjelasan, berargumen dengan baik, memecahkan masalah dan memahami hal-hal kompleks yang mana kemampuan-kemampuan tersebut memperlihatkan bagaimana siswa menggunakan nalarnya (Sofyan, 2019). 
Kualitas suatu DKL dapat ditentukan berdasarkan karakteristik konstruksi pengetahuan. Analisis ini didasarkan pada kemunculan komponen Diagram Vee menurut Novak \& Gowin Konstruksi pengetahuan melibatkan proses membangun pemahaman konsep berdasarkan proses mengobservasi objek/ fenomena, mencatat dan mentransformasi data, serta menghubungkan teori dengan hasil pengamatan. Komponen pertanyaan fokus dan objek/fenomena memiliki skor maksimal 3, sementara pada komponen teori, prinsip, dan konsep; perekaman dan transformasi data; dan perolehan pengetahuan memiliki skor maksimal 4. Hasil analisis aspek konstruksi pengetahuan pada DKL lapangan dapat dilihat pada Tabel 3.

Tabel 3. Hasil Analisis Aspek Konstruksi Pengetahuan

\begin{tabular}{|c|c|c|c|c|c|c|}
\hline \multirow[t]{2}{*}{ Parameter } & \multicolumn{5}{|c|}{ LKPD } & \multirow[t]{2}{*}{ Skor } \\
\hline & A & B & C & D & E & \\
\hline Judul, Tujuan atau pertanyaan fokus & 2 & 3 & 3 & 2 & 3 & 2,6 \\
\hline Objek Fenomena & 1 & 2 & 3 & 1 & 2 & 1,8 \\
\hline Teori, prinsip dan konsep & 2 & 2 & 2 & 2 & 2 & 2 \\
\hline Perekaman dan transformasi data & 1 & 3 & 3 & 2 & 1 & 2 \\
\hline Perolehan pengetahuan & 1 & 2 & 2 & 1 & 2 & 1,6 \\
\hline
\end{tabular}

Berdasarkan hasil analisis, dapat disimpulkan bahwa sebagian besar DKL dari kurikulum 1994 hingga 2013 sudah terdapat judul/tujuan/pertanyaan fokus, tetapi tidak memfokuskan kepada hal utama yang berkaitan dengan objek dan peristiwa. Sebagian besar DKL yang dianalisis, peristiwa dan objeknya sudah dapat diidentifikasi tetapi tidak konsisten dengan pertanyaan fokus. (Novak, J., Gowin, D., \& Kahle, 1984) mengungkapkan bahwa pertanyaan fokus harus mengarahkan pada objek/fenomena yang harus diobservasi. Pertanyaan fokus pada DKL dapat mengarahkan siswa untuk memperoleh apa yang seharusnya mereka peroleh/ temukan melalui kegiatan laboratorium (Abrahams \& Millar, 2008). Pada Tabel 3 terlihat bahwa komponen teori, prinsip, dan konsep diperoleh belum menunjukan capaian yang baik dimana semua DKL menunjukan skor 2, dimana konsep dan teori yang relevan bisa teridentifikasi. Hal yang sama terjadi pada komponen perekaman dan transformasi. Jika komponen perekaman dan transformasi data tidak terdapat pada DKL, maka kegiatan tersebut kurang memfasilitasi proses metakognitif siswa dalam memahami dan memaknai hasil observasi (Wahidah, N.S, Suptriatno, B, Kusumastuti, 2018). Temuan juga menjelaskan DKL yang dianalisis belum mengarah pada perolehan pengetahuan. Hal ini dikarenakan proses penarikan kesimpulan sampai dengan memperoleh perolehan pengetahuan masih lemah karena pertanyaan yang belum terstuktur (Ekselsa et al., n.d.).

\section{Hasil Uji Coba DKL Pteridophyta Terpilih}

Uji coba Desain Kegiatan Laboratorium (DKL) terhadap salah satu DKL Pteridophyta dilakukan untuk melihat kekurangan serta kelebihan dari DKL yang ada. Adapun DKL yang digunakan untuk uji coba ialah DKL D. Pemilihan DKL tersebut didasarkan pada kurikulum yang diterapkan di kebanyakan sekolah adalah 2013 revisi dan kurikulum sebelum-sebelumnya sudah jarang digunakan. Adapun tahapan-tahapan praktikum dilaksanakan sesuai dengan tahapan yang tertera pada DKL yang diuji.

Berdasarkan hasil uji coba DKL Pteridophyta yang terpilih dari segi konten dan kompetensi telah memenuhi standar minimal KD pada kurikulum 2013 revisi yang berlaku pada saat DKL tersebut terbit. Namun ketika dilakukan uji coba, terdapat ketidaksesuaian antara langkah kerja dengan pertanyaan diskusi. Pada langkah kerja juga memuat perintah yang tidak dijelaskan secara rinci bagian mana dan parameter apa yang harus diamati dengan menggunakan alat tersebut sehingga dapat menimbulkan 
persepsi yang berbeda-beda. Data pengamatan hanya direpresentasikan dalam bentuk gambar, kemudian dideskripsikan. Selain itu, secara keseluruhan pertanyaan diskusi belum mengembangkan keterampilan berpikir tingkat tinggi dan dan kurang menggali serta tidak konsisten dengan data hasil pengamatan. Dari pertanyaan pengarah hanya bisa menemukan konsep ciri-ciri morfologi Pteridophyta saja sedangkan tujuan praktikum pada DKL tersebut menuntut untuk sampai pada perenapan prinsip klasifikasi untuk menggolongkan tumbuhan paku (Pteridophyta) tersebut.

\section{Rekonstruksi DKL}

Setelah melakukan tahapan analisis dan uji coba, maka peneliti mencoba menyusun DKL pada materi pteridophyta dengan menggunakan pendekatan fenetik. Hal tersebut didasarkan pada hasil temuan analisis dan ujicoba yang telah memuat kelemahan-kelemahan yang terdapat pada DKL Pteridophyta. Rekonstruksi ini bertujuan agar DKL Pteridophyta lebih efektif dan representatif baik dari segi relevansi, kompetensi dan konstruksi pengetahuan untuk siswa SMA pada kurikulum 2013 revisi terbaru yang berlaku saat ini, yaitu menyajikan laporan hasil pengamatan dan analisis fenetik dan filogenetik tumbuhan serta peranannya dalam kehidupan, Rancangan DKL hasil rekonstruksi dapat dilihat seperti di bawah ini.

\section{Analisis Fenetik Tumbuhan Paku (Pteridophyta)}

\section{A. Tujuan:}

1. Mengidentifikasi ciri-ciri morfologi tumbuhan paku (pteridophyta).

2. Membuat fenogram divisio tumbuhan paku (pteridophyta).

\section{B. Alat dan Bahan:}

- Alat : Lup

- Bahan : 5 jenis tumbuhan paku berbeda yang ditemukan di lingkungan sekitar peserta didik.

\section{Langkah Kerja:}

Kegiatan 1.

Amati dan identifikasi dengan cermat bagian akar, rimpang, daun, sorus, dan habitat masingmasing tumbuhan paku. Kemudian gambar dan catat hasil identifikasi pada kolom dan tabel hasil pengamatan yang disediakan.

\section{Tabel Hasil Pengamatan}

Gambar Hasil Pengamatan

\begin{tabular}{|l|l|l|}
\hline 1. & 2. & 3. \\
& & \\
\hline 4. & 5. & \\
\hline & & \\
& & \\
\hline
\end{tabular}




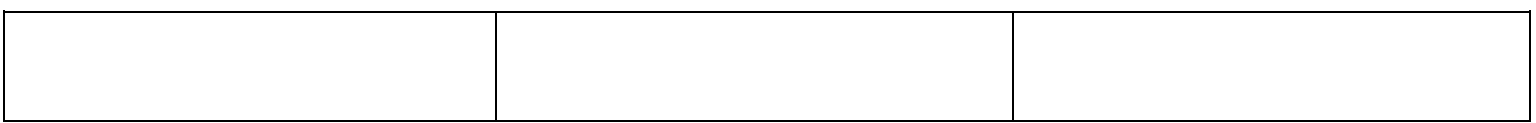

Hasil Identifikasi

\begin{tabular}{|l|l|l|l|l|l|}
\hline \multirow{2}{*}{ No. } & Nama Tumbuhan paku & \multicolumn{3}{|c|}{ Hasil Identifikasi } & Habitat \\
\cline { 3 - 6 } & & $\begin{array}{c}\text { Penampakan } \\
\text { rimpang }\end{array}$ & Tipe daun & Letak sorus & \\
\hline 1. & & & & & \\
\hline 2. & & & & & \\
\hline 3. & & & & & \\
\hline 4. & & & & & \\
\hline 5. & & & & & \\
\hline
\end{tabular}

\section{Pertanyaan:}

1. Tumbuhan apa saja yang memiliki persamaan?

2. Tumbuhan apa saja yang dapat dijadikan dalam kelompok yang sama?

3. Apa yang menjadi dasar pengelompokan tumbuhan pada soal no 2 ?

\section{Kegiatan 2.}

1. Tentukanlah unit-unit taksonomi operasional (OTU) yang akan dikaji (Spesies tumbuhan yang akan dikaji)

2. Pilihlah karakter yang dimiliki/ tidak oleh setiap spesies, dan memilih karakter yang dominan.

3. Berikan simbol (1) untuk karakter tanaman yang dimiliki, simbol (0) untuk karakter tanaman yang tidak dimiliki.

4. Buatlah matrik kesamaan dengan menhubungkan (1/0) yang sama.

5. Lakukan clustering, diurutkan dari tanaman yang memiliki angka kesamaan tertinggi hingga terkecil

6. Buatlah fenogram.

Hasil kajian:

1. Tuliskan spesies yang diidentifikasi pada langkah kerja 1

\begin{tabular}{|c|c|c|}
\hline No. & Nama Spesies & Simbol Spesies \\
\hline 1. & & A \\
\hline 2. & & B \\
\hline 3. & & C \\
\hline 4. & & D \\
\hline 5. & E \\
\hline
\end{tabular}

2. Pilih karakter dominan yang yang dimiliki atau yang tidak dimiliki setiap spesies.

\begin{tabular}{|c|l|l|}
\hline No. & \multicolumn{1}{|c|}{ Hal yang diamati } & Karakter \\
\hline 1. & Penampakan rimpang & \\
\hline 2. & Tipe daun & \\
\hline 3. & Letak sorus & \\
\hline 4. & Habitat & \\
\hline
\end{tabular}

3. Isilah tabel berikut dengan tanda (1) jika spesies memiliki karakter tersebut dan (0) jika spesies tersebut tidak memiliki karakter tersebut.

\begin{tabular}{|c|c|c|c|c|c|c|}
\hline No. & Karakter & A & B & C & D & E \\
\hline 1. & & & & & & \\
\hline 2. & & & & & & \\
\hline
\end{tabular}




\begin{tabular}{|c|l|l|l|l|l|l|}
\hline 3. & & & & & & \\
\hline 4. & & & & & & \\
\hline
\end{tabular}

4. Isilah Tabel Matrik kesamaan dibawah ini dengan simbol (1)/(0) untuk menghitung koefisien kesamaan.

\begin{tabular}{|c|c|c|c|c|}
\hline Spesies Karakter & 1 & 2 & 3 & 4 \\
\hline A & & & & \\
\hline B & & & & \\
\hline C & & & & \\
\hline D & & & & \\
\hline E & & & & \\
\hline
\end{tabular}

Koefisien kesamaan dapat dihutung dengan rumus berikut:

$A B=$ Jumlah karakter $A$ yang sama dengan $B / 4=$

$A C=$ Jumlah karakter $A$ yang sama dengan $C / 4=$....

$A D=$ Jumlah karakter $A$ yang sama dengan $D / 4=$....

$\mathrm{AE}=$ Jumlah karakter $\mathrm{A}$ yang sama dengan $\mathrm{E} / 4=$....

$\mathrm{BC}=$ Jumlah karakter $\mathrm{B}$ yang sama dengan $\mathrm{C} / 4=$

$\mathrm{BD}=$ Jumlah karakter $\mathrm{B}$ yang sama dengan $\mathrm{D} / 4=$

$\mathrm{BE}=$ Jumlah karakter $\mathrm{B}$ yang sama dengan $\mathrm{E} / 4=$

$C D=$ Jumlah karakter $C$ yang sama dengan $D / 4=$

$\mathrm{CE}=$ Jumlah karakter $\mathrm{C}$ yang sama dengan $\mathrm{E} / 4=\ldots$

$\mathrm{DE}=$ Jumlah karakter $\mathrm{D}$ yang sama dengan $\mathrm{E} / 4=$

Isilah tabel dibawah ini dengan hasil perhitungan koefisien kesamaan.

\begin{tabular}{|c|c|c|c|c|c|}
\hline & A & B & C & D & E \\
\hline A & 1 & & & & \\
\hline B & & 1 & & & \\
\hline C & & & 1 & & \\
\hline D & & & & 1 & \\
\hline E & & & & & 1 \\
\hline
\end{tabular}

5. Lakukan clustering.

6. Buatlah fenogram dengan ketentuan sumbu $Y$ nilai kooefisien kesamaan dan sumbu $X$ untuk spesies. 
Pertanyaan:

1. Dari fenogram di atas spesies manakah yang berkerabat dekat?

2. Dari fenogram ada berapa kelompok spesies yang dikaji?

\section{E. KESIMPULAN}

\section{SIMPULAN}

DKL Pteridophyta yang ditemukan dari berbagai kurikulum setelah dilakukan analisis dan uji coba ternyata masih terdapat kekurangan pada berbagai aspek. Kekurangan ini tentunya akan membuat praktikum yang dilakukan tidak bisa menunjang pembentukan pengetahuan siswa yang sesuai dengan tujuan pembelajaran. Kekurangan yang paling sering ditemukan utamanya dalam kesesuaian DKL dengan kurikulum yang tentunya akan memengaruhi level kemampuan berpikir siswa. Temuan dari hasil analisis dan uji coba tersebut menjadi dasar bagi peneliti untuk merekonstruksi DKL. Pada DKL rekonstruksi ditambahkan pendekatan fenetik untuk menyelaraskan dengan kompetensi dasar yang telah dirumuskan pada kurikulum 2013 revisi yang berlaku saat ini. DKL rekonstruksi dirancang untuk mengembangkan keterampilan abad 21 diantaranya keterampilan proses sains sesuai tuntutan era revolusi industri 4.0. Salah satu keterampilan proses sains yang dapat dikembangkan adalah keterampilan berkomunikasi, peserta didik dituntut agar mampu menyampaikan hasil penemuannya kepada orang lain dan disampaikan dalam bentuk laporan penelitian atau paper. Harapannya DKL rekonstruksi ini dapat menjadi alternatif yang sesuai dan representatif dengan standar kurikulum yang berlaku, serta dapat menjadi rujukan untuk bahan ajar siswa.

\section{UCAPAN TERIMA KASIH}

Penulis mengucapkan terimakasih sebesar-besarnya kepada Bapak Dr. Bambang Supriatno, M.Si dan Ibu Dr. Sri Anggraeni, M.Si selaku dosen pembimbing atas arahan dan bimbingannya. Selain itu terimakasih saya ucapkan terimakasih kepada Bapak Ali Sadikin dari pihak Jurnal Biodik yang telah memfasilitasi informasi mengenai publikasi jurnal.

\section{RUJUKAN}

Abrahams, I., \& Millar, R. (2008). Does practical work really work? A study of the effectiveness of practical work as a teaching and learning method in school science. International Journal of Science Education, 30(14), 1945-1969. https://doi.org/10.1080/09500690701749305

Ekselsa, R. A., Supriatno, B., \& Anggraeni, S. (n.d.). BIODIK: Jurnal IImiah Pendidikan Biologi Rekonstruksi dan Pengembangan Lembar Kerja Siswa pada Materi Plantae Submateri Spermatophyta dengan Pendekatan Keterampilan Proses (Reconstruction and Development of Student Worksheets on the Spermatophyta Submater. https://online-journal.unja.ac.id/biodik

Hidayat, T. (2017). Menggairahkan pembelajaran taksonomi di kelas menggunakan metode fenetik. Tersedia: Https:/Www. Researchgate. Net/Publication ..., February. https://www.researchgate.net/profile/Topik_Hidayat/publication/313525815_Menggairahkan_pemb elajaran_taksonomi_di_kelas_menggunakan_metode_fenetik/links/589d5c1192851c599c975c4d/ Menggairahkan-pembelajaran-taksonomi-di-kelas-menggunakan-metode-fenetik.pdf

Laelasari, I., \& Supriatno, B. (2018). Analisis komponen penyusun desain kegiatan laboratorium bioteknologi [Universitas Ahmad Dahlan, Kampus 3]. In JURNAL BIOEDUKATIKA (Vol. 6, Issue 2). https://doi.org/10.26555/bioedukatika.v6i2.10592

Lase, D. (2019). Pendidikan di Era Revolusi Industri 4.0 [STT BNKP Sundermann]. In SUNDERMANN: 
Jurnal IImiah Teologi, Pendidikan, Sains, Humaniora dan Kebudayaan (Vol. 12, Issue 2). https://doi.org/10.36588/sundermann.v1i1.18

Murni, R. L. F., Harlita, \& Widoretno, S. (2017). Penerapan Guided Inquiry Learning untuk Meningkatkan Keterampilan Interpretasi Data Siswa Kelas XI IPA 4 Tahun Pelajaran 2016 / 2017 pada Materi Sistem Ekskresi Manusia. Proceeding Biology Education Conference, 14(1), 355360. https://jurnal.uns.ac.id/prosbi/article/view/18812

Novak, J., Gowin, D., \& Kahle, J. (1984). Learning How to Learn. Cambridge: Cambridge University Press. https://doi.org/10.1017/CBO9781139173469

Oktaviani, F., \& Hidayat, T. (2015). Profil Keterampilan Berkomunikasi Siswa Sma Menggunakan Metode Fenetik Dalam Pembelajaran Klasifikasi Arthropoda. Jurnal Pengajaran Matematika Dan IImu Pengetahuan Alam, 15(1), 13. https://doi.org/10.18269/jpmipa.v15i1.288

Sisri, E. M., Anggraeni, S., Supriatno, B., Studi, P., Biologi, P., \& Keguruan, F. (n.d.). BIODIK: Jurnal IImiah Pendidikan Biologi Analisis dan Rekonstruksi Lembar Kerja Siswa Materi Spermatophyta Dengan menerapkan Analisis Fenetik (Analysis and Reconstruction of Practical Work Spermatophyta Material By applying Phenetic Analysis). https://online-journal.unja.ac.id/biodik

Sofyan, F. A. (2019). Implementasi Hots Pada Kurikulum 2013. Inventa, 3(1), 1-9. https://doi.org/10.36456/inventa.3.1.a1803

Wahidah, N.S, Suptriatno, B, Kusumastuti, M. N. (2018). Analisis Struktur dan Kemunculan Tingkat Kognitif pada Desain Kegiatan Laboratorium Materi Fotosintesis. 7260(2), 70-76. 